\title{
The targeting of non-coding RNAs by curcumin: Facts and hopes for cancer therapy (Review)
}

\author{
YUN LIU $^{1 *}$, HONGMEI SUN ${ }^{2 *}$, BOLAT MAKABEL ${ }^{3 *}$, QINGBIN CUI $^{4,5}$, JIAJUN LI $^{1}$, \\ CHAOYUE SU ${ }^{1}$, CHARLES R. ASHBY $\mathrm{Jr}^{4}$, ZHESHENG CHEN ${ }^{4}$ and JIANYE ZHANG ${ }^{1}$
}

\begin{abstract}
${ }^{1}$ Guangdong Provincial Key Laboratory of Molecular Target and Clinical Pharmacology, School of Pharmaceutical Sciences and The Fifth Affiliated Hospital, Guangzhou Medical University, Guangzhou, Guangdong 511436, P.R. China;

${ }^{2}$ Infinitus (China) Company Ltd., Jiangmen, Guangdong 529156, P.R. China; ${ }^{3}$ Xinjiang Institute of Materia Medica, Urumqi,

Xinjiang 830004, P.R. China; ${ }^{4}$ College of Pharmacy and Health Sciences, St. John's University, Queens, New York,

NY 11439, USA; ${ }^{5}$ College of Public Health, Guangzhou Medical University, Guangzhou, Guangdong 511436, P.R. China
\end{abstract}

Received December 14, 2018; Accepted April 24, 2019

DOI: $10.3892 / o r .2019 .7148$

\begin{abstract}
Curcumin [(1E,6E)-1,7-bis(4-hydroxy-3methoxyphenyl) hepta-1,6-diene-3,5-dione] is a natural polyphenol that is derived from the turmeric plant (curcuma longa L.). Curcumin is widely used in food coloring, preservatives, and condiments. Curcumin possesses anti-tumor, anti-oxidative and anti-inflammatory efficacy, as well as other pharmacological effects. Emerging evidence indicates that curcumin alters microRNAs (miRNAs) and long non-coding RNAs (lncRNAs) in various types of cancers. Both miRNAs and lncRNAs are non-coding RNAs that can epigenetically modulate the expression of multiple genes via post-transcriptional regulation. In the present review, the interactions between curcumin and non-coding RNAs are summarized in numerous types of cancers, including lung, colorectal, prostate, breast, nasopharyngeal, pancreatic, blood, and ovarian cancer, and the vital non-coding RNAs and their downstream targets are described.
\end{abstract}

\section{Contents}

1. Introduction

2. Curcumin regulates cancer miRNAs

Correspondence to: Professor Jianye Zhang, Guangdong Provincial Key Laboratory of Molecular Target and Clinical Pharmacology, School of Pharmaceutical Sciences and The Fifth Affiliated Hospital, Guangzhou Medical University, Xinzao, Panyu, Guangzhou, Guangdong 511436, P.R. China

E-mail: jianyez@163.com

Professor Zhesheng Chen, College of Pharmacy and Health Sciences, St. John's University, 8000 Utopia Parkway, Queens, New York, NY 11439, USA

E-mail: chenz@stjohns.edu

${ }^{*}$ Contributed equally
3. Curcumin regulates cancer lncRNAs

4. Conclusions and perspectives

\section{Introduction}

Cancer is one of the leading causes of human diseases and death due to the high rates of morbidity and mortality (1-4). Currently, chemotherapy, one of the primary therapeutic strategies, exerts its efficacy by multiple mechanisms, such as induction of apoptosis and inhibition of tumor growth (5-8).

Abbreviations: miRNA, microRNA; lncRNA, long non-coding RNA; mRNA, messenger RNA; oncomiRNA, oncogenic miRNA; CLL, chronic lymphocytic leukemia; pri-miRNA, primary miRNA; RISC, RNA-induced silencing complex; SCLC, small cell lung cancer; NSCLC, non-small cell lung cancer; PI3K, phosphoinositide 3-kinase; MMP, matrix metalloproteinase; EZH2, zeste homolog 2; PTEN, phosphatase and tensin homolog; CRC, colorectal cancer; EMT, epithelial-to-mesenchymal transition; PRC, polycomb repressive complex; PDCD4, programmed cell death protein 4; AKBA, 3-acetyl-11-keto- $\beta$-boswellic acid; PEG10, paternally expressed gene-10; Sp, specificity protein; PGK1, phosphoglycerate kinase-1; FOXD3, forkhead box D3; HuPCaSC, human prostate cancer stem cell; NPC, nasopharyngeal carcinoma; TP53, tumor protein 53; Skp2, S-phase kinase-associated protein 2; XIAP, X-linked inhibitor of apoptosis; SET8, SET domain-containing lysine methyltransferase 8; OCT4, octamer-binding transcription factor 4; SOX-2, (sex determining region Y)-box 2; Nano-CUR, nanoparticle formulation of curcumin; MALAT1, metastasis-associated lung adenocarcinoma transcript 1; HOTAIR, HOX transcript antisense RNA; SOX2-OT, SOX2 overlapping transcript; MEG3, maternally expressed 3; PANDAR, promoter of CDKN1A antisense DNA damage-activated RNA; GAS5, growth arrest-specific 5; UCA1, urothelial cancer associated-1; PCA3, prostate cancer antigen-3; NEAT1, nuclear-enriched abundant transcript-1

Key words: curcumin, natural product, food, diet, miRNA, lncRNA, cancer, epigenetic pharmacology 
Numerous studies have been focused on natural products (9-12) as they are an important source of novel anti-cancer drugs, targeting various key proteins and the DNA of cancer cells $(5,13,14)$. Curcumin [(1,7-bis(4-hydroxy-3-methoxyphen yl)-1,6-heptane-3,5-dione] is a yellow pigment present in the rhizome of Curcuma longa Linn (15). Curcumin (Fig. 1) is the principal constituent of turmeric, a popular Indian spice. Being reported to have pharmacological properties, curcumin may be useful for treating cancer, Dejerine-Sottas disease, inflammation, ulcer, depression, contraception, diabetes, and viral diseases, among others (16).

Accumulating data has suggested that curcumin decreases the proliferation of various cancer cells by inhibiting cell growth, migration, and invasion. In addition, curcumin has been reported to induce apoptosis and growth repression of cancer cells in vivo and in vitro. Recent studies have suggested that curcumin exerts epigenetic regulatory effects on non-coding RNAs in various cancers $(17,18)$. Depending on their length, non-coding RNAs are classified as short non-coding (snc) or long non-coding (lnc) RNAs $(19,20)$.

\section{Curcumin regulates cancer microRNAs (miRNAs)}

Biogenesis and function of miRNA. Endogenous miRNAs are non-coding RNAs that are $\sim 22$ nucleotides in length, which play important roles in post-transcriptional regulation, inhibiting target messenger RNA (mRNA) translation by complementary binding to the 3 '-untranslated region (3'-UTR) of mRNAs $(21,22)$. Consequently, miRNAs either repress translation or initiate mRNA degradation $(23,24)$. It has been reported that one miRNA may bind to different mRNAs, and each mRNA can be targeted by many different miRNAs, emphasizing the important regulatory role of miRNAs $(25,26)$. The first miRNA was discovered in 1993, and the term 'microRNA' was first used in 2001. Currently, at least 2,000 miRNAs associated with the human genome are known, the majority of which are abnormal in tumors $(27,28)$. Numerous miRNAs may be classified as oncogenic miRNAs (oncomiRNAs) as they facilitate the proliferation and progression of certain cancers (e.g., lung cancer, breast cancer, and esophageal carcinoma) by downregulating genes via translational repression and mRNA destabilization mechanisms (10). Furthermore, miRNAs are also important prognostic biomarkers of chronic lymphocytic leukemia (CLL), pancreatic cancer, neuroblastoma, and colorectal cancer $(29,30)$. It is well established that miRNAs are central mediators in cancer biology, mediating the network communication between cancer cells and their microenvironments (13).

miRNA biogenesis consists of several steps (Fig. 2), starting in the nucleus, where miRNAs are transcribed into a hairpin-shaped primary miRNA (pri-miRNA), catalyzed by RNA polymerase II. Subsequently, pri-miRNAs, which are hundreds to thousands of nucleotides in length, are biotransformed into pre-miRNAs ( 70 nucleotides in length) in the nucleus by the microprocessor complex containing the protein, Pasha/DGCR8, and the RNase III enzyme, Drosha. Subsequently, pre-miRNA in the nucleus is transported to the cytoplasm through nuclear pores via the protein, exportin 5. In the cytoplasm, pre-miRNA is cleaved by a helicase containing

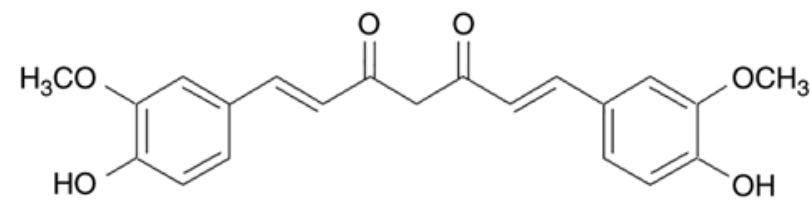

Figure 1. Chemical structure of curcumin.

an RNase motif (known as Dicer) to produce the functional miRNA, with a length of $21-23$ nucleotides (31-33).

The functional miRNA is recruited by Argonaute proteins into the RNA-induced silencing complex (RISC). Finally, the single-stranded mature miRNA combines with RISC, producing inhibition of translation or degradation of the mRNA by binding to the 3'-UTR of the target mRNA $(34,35)$. Recent evidence indicates that miRNAs can be extracellularly bound to lipoproteins (36). Also, miRNAs may be loaded into extracellular vesicles and transferred to receptor cells, inducing remote effects as a form of cell-to-cell communication (37).

miRNAs may suppress cancer (Fig. 3) or exert oncogenic effects (Fig. 4). The function of miRNAs in tumor progression was first reported by Calin et al (38), whose research demonstrated that miR-16 and miR-15 are downregulated in patients with CLL. Currently, thousands of miRNAs have been proven to be dysregulated in other types of human cancer, and some of these miRNAs appear to serve an important role in carcinogenesis by altering the expression of oncogenes and cancer suppressor genes $(16,39)$.

Curcumin effects on miRNAs in lung cancer. Lung cancer is the leading cause of mortality among cancer-associated deaths globally, resulting in at least 1.5 million deaths each year $(40,41)$. Lung cancer is categorized into two fundamental histological subtypes: Small cell lung cancer (SCLC; 15-20\% incidence) and non-small cell lung cancer (NSCLC; 80-85\% incidence) (42). Recent evidence has indicated that an association exists between lung cancer and miRNA expression, suggesting that this could be used as a novel treatment strategy $(43,44)$. The miRNAs of lung cancer modulated by curcumin are summarized in Table I.

Curcumin has been shown to markedly increase miR-192-5p expression, and suppress the phosphoinositide 3-kinase (PI3K)/Akt signaling pathway, in A549 cells. Furthermore, miR-192-5p mimics may significantly increase the efficacy of curcumin in cell viability inhibition, apoptosis induction, and suppression of the PI3K/Akt signaling pathway. Furthermore, anti-miR-192-5p mimics abolish the cytotoxicity of curcumin and PI3K/Akt pathway suppression produced by curcumin in A549 cells $(44,45)$.

The metastasis of lung cancer has been shown to be positively correlated with suboptimal clinical results and increased mortality. In A549 cells, curcumin markedly enhances the expression of $\mathrm{miR}-98$, and the expression of its downstream target, the LIN28A gene, which is correlated with the self-renewal capacity of stem cells, is decreased. The matrix metalloproteinases (MMPs) MMP2 and MMP9, which are downstream proteins of LIN28A, are downregulated in vitro and in vivo upon treatment with curcumin. 


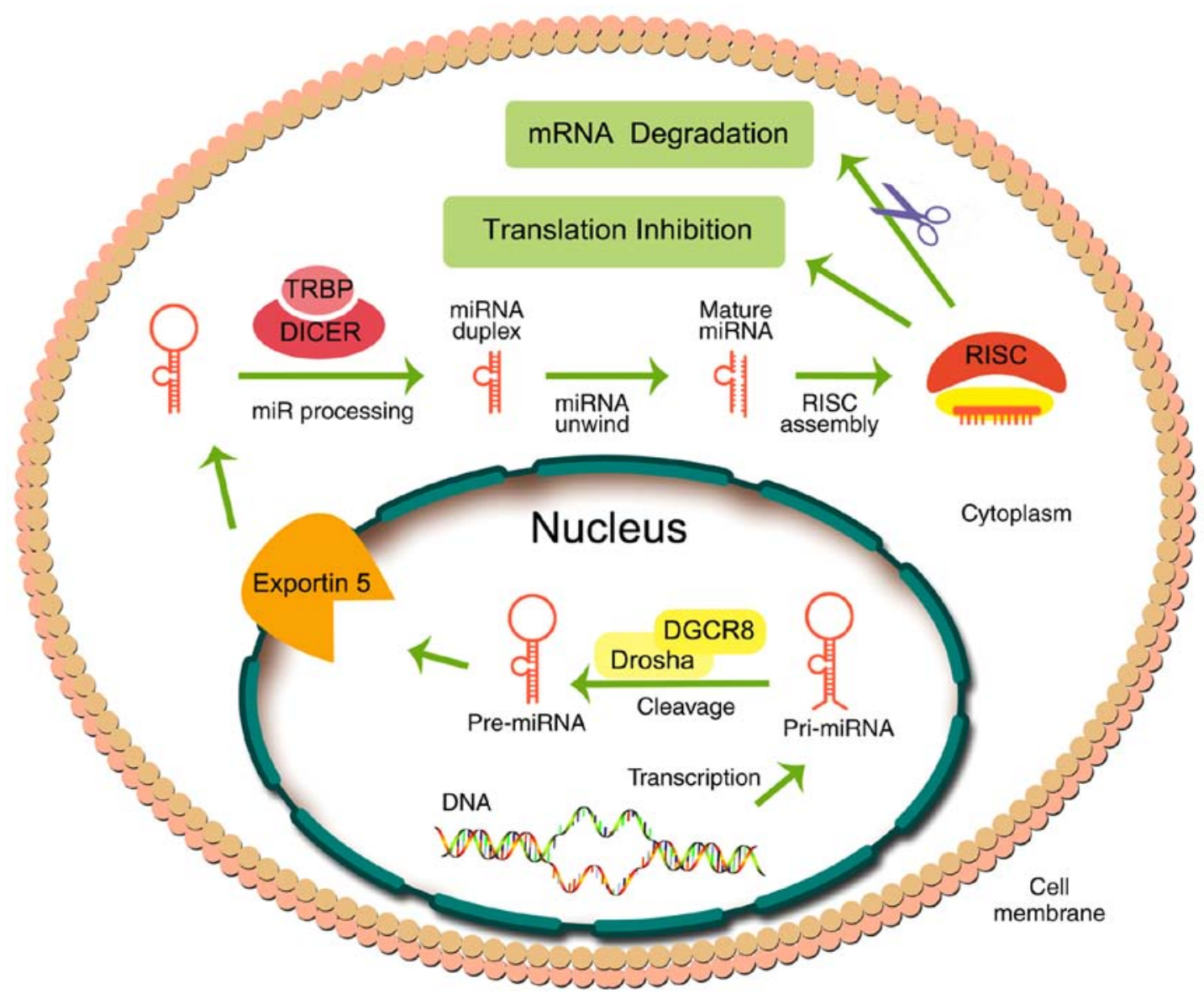

Figure 2. Biogenesis of miRNA and its function. RISC, RNA-induced silencing complex; pri-miRNA, primary miRNA; TRBP, trans-activation response RNA-binding protein.

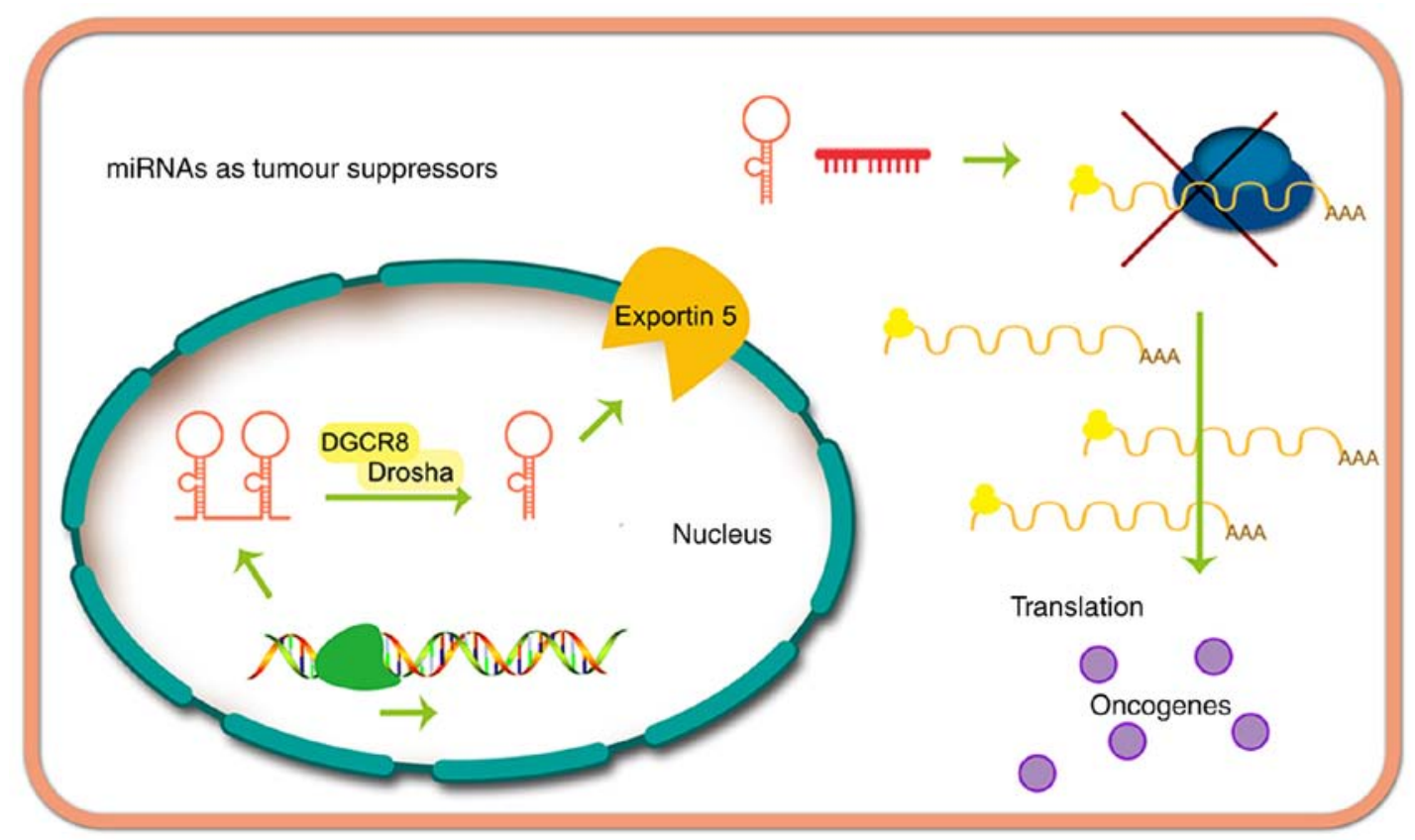

Figure 3. miRNAs act as tumor suppressors. OncomiR, oncogenic miRNA.

Furthermore, curcumin at a concentration of $100 \mu \mathrm{M}$ was shown to induce LIN28A-induced migration and invasion in A549 cells (46).
Curcumin at concentrations of 5,10,20,30, and $40 \mu \mathrm{M}$ led to a marked induction of apoptosis, also exhibiting anti-cancer efficacy in drug-sensitive A549 cells and multidrug-resistant 
Table I. Curcumin modulates miRNAs in lung cancer.

\begin{tabular}{|c|c|c|c|c|}
\hline Author, year & Cell line & miRNA & Downstream target(s) & (Refs.) \\
\hline Jin et al, 2015 & NCL-H460, A549 & miR-192-5p ( $\uparrow)$ & PI3K/Akt & (45) \\
\hline Liu et al, 2017 & A549 & miRNA-98 ( $\uparrow)$ & $\begin{array}{l}\text { LIN28A } \\
\text { MMP2 } \\
\text { MMP9 }\end{array}$ & (46) \\
\hline Zhang et al, 2010 & A549/DDP & $\operatorname{miR}-186^{*}(\downarrow)$ & Caspase-10 & (47) \\
\hline Ye et al, 2015 & $\mathrm{H} 460, \mathrm{~A} 427$ & $\begin{array}{l}\operatorname{miR}-192-5 p(\uparrow) \\
\operatorname{miR}-215(\uparrow)\end{array}$ & XIAP & (48) \\
\hline Wu et al, 2016 & $\begin{array}{l}\text { A549, NCI-H520, } \\
\text { NCI-H1373, } \\
\text { NCI-H2170 }\end{array}$ & $\begin{array}{l}\text { let 7c }(\uparrow) \\
\text { miR-101 }(\uparrow)\end{array}$ & $\begin{array}{l}\text { EZH2 } \\
\text { NOTCH1 }\end{array}$ & (50) \\
\hline Zhang et al, 2014 & A549 & $\operatorname{miR}-21(\downarrow)$ & PTEN & (51) \\
\hline
\end{tabular}

The upwards and downwards pointing arrows indicate up- and downegulation, respectively. PI3K, phosphoinositide 3-kinase; MMP, matrix metalloproteinase; PTEN, phosphatase and tensin homolog; EZH2, enhancer of zeste homolog 2.

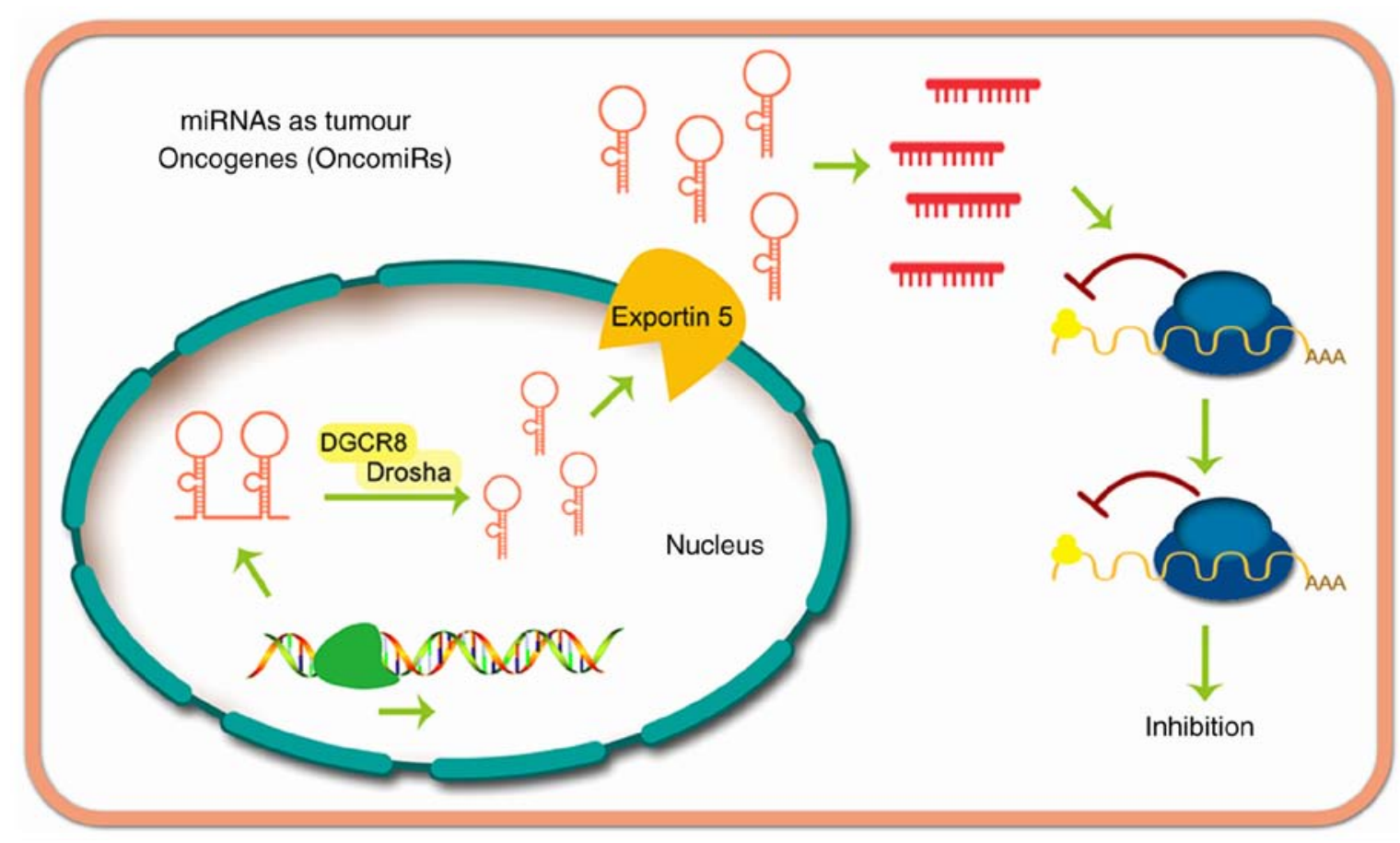

Figure 4. miRNAs act as tumor oncogenes.

A549/DDP cells. Curcumin markedly downregulated miR-186* expression in A549 and A549/DDP cells, whereas transfection with an miR-186* inhibitor was shown to increase apoptosis of the A549 and A549/DDP cells. By contrast, the overexpression of miR-186* markedly inhibited curcumin-induced apoptosis in A549 and A549/DDP cells (47).

Curcumin has been reported to affect different miRNAs in various cell lines. For example, RT-qPCR and miRNA microarray data indicated that miR-215 and miR-192-5p are the most responsive miRNAs in A427 and H460 cells following incubation with curcumin (48). Curcumin was also shown to regulate the levels of key miRNAs in A549 cells that were detected by microarray analysis, such as miR-330-5p, which was maximally upregulated by curcumin in vitro (49).

Curcumin inhibits the growth and metastasis of lung cancer cells, including the NCI-H2170, NCI-H520, NCI-H1373, and A549 cell lines. Furthermore, curcumin can suppress the expression of the mRNA that codes for the protein, enhancer of zeste homolog 2 (EZH2), by increasing the levels of miR-101 and let-7c. Curcumin has been shown to downregulate the expression of NOTCH1 by inhibiting EZH2. Interestingly, reciprocal interactions have been identified between NOTCH1 and EZH2 in A549, NCI-H520, NCI-H1373, and NCI-H2170 lung cancer cells (50). 
Table II. Curcumin modulates miRNAs in colorectal cancer.

\begin{tabular}{|c|c|c|c|c|}
\hline Author, year & Cell line & miRNA & Downstream target(s) & (Refs.) \\
\hline $\begin{array}{l}\text { Toden et al, 2015; } \\
\text { Goel, } 2017\end{array}$ & $\begin{array}{l}\text { HCT116, } \\
\text { HCT116-5FUR }\end{array}$ & $\begin{array}{l}\operatorname{miR}-200 b(\uparrow) \\
\operatorname{miR}-200 \mathrm{c}(\uparrow) \\
\operatorname{miR}-141(\uparrow) \\
\operatorname{miR}-429(\uparrow) \\
\operatorname{miR}-101(\uparrow)\end{array}$ & $\begin{array}{l}\text { EZH2 } \\
\text { BMI1 } \\
\text { SUZ12 } \\
\text { Ring1B }\end{array}$ & $(54,55)$ \\
\hline $\begin{array}{l}\text { Mudduluru et al, 2011; } \\
\text { Riaz Rajoka et al, } 2018\end{array}$ & Rko, HCT116 & $\operatorname{miR}-21(\downarrow)$ & Pdcd4 & $(56,57)$ \\
\hline Toden et al, 2015 & $\begin{array}{l}\text { HCT116, } \\
\text { SW480 }\end{array}$ & $\begin{array}{l}\operatorname{miR}-34 \mathrm{a}(\uparrow) \\
\operatorname{miR}-27 \mathrm{a}(\downarrow)\end{array}$ & $\begin{array}{l}\text { FBXW7 } \\
\text { CDK4, } 6 \\
\text { Cyclin D, E } \\
\text { c-Myc }\end{array}$ & (58) \\
\hline Li et al, 2018 & HCT116 & miR-491 ( $\uparrow)$ & PEG10 & (59) \\
\hline Gandhy et al, 2012 & RKO, SW480 & $\begin{array}{l}\operatorname{miR}-27 \mathrm{a}(\downarrow) \\
\operatorname{miR}-20 \mathrm{a}(\downarrow) \\
\operatorname{miR}-17-5 \mathrm{p}(\downarrow)\end{array}$ & $\begin{array}{l}\text { Sp1 } \\
\text { Sp3 } \\
\text { Sp4 }\end{array}$ & $(60)$ \\
\hline Dou et al, 2017 & SW480 & miR-130a $(\downarrow)$ & Wnt $/ \beta$-catenin & (61) \\
\hline
\end{tabular}

The upwards and downwards pointing arrows indicate up- and downegulation, respectively. EZH2, enhancer of zeste homolog 2; FBWX7, F-box and WD repeat domain containing 7; Pdcd4, programmed cell death 4; CDK, cyclin-dependent kinase.

It has been reported that curcumin leads to a marked inhibition of cell growth, and induces apoptosis in A549 cells. Curcumin produces a concentration-dependent repression of miRNA-21 expression. Phosphatase and tensin homolog (PTEN) is the downstream target gene of miRNA-21, which is markedly increased in A549 cells upon incubation with curcumin. The transfection of A549 cells with PTEN small interfering RNA or a microRNA-21 mimic significantly reversed curcumin-induced growth inhibition and apoptosis (51).

Curcumin and miRNAs in colorectal cancer (CRC). CRC is a commonly occurring type of cancer that produces substantial morbidity and mortality rates globally in both males and females. Despite the significant progress has been achieved in the treatment of CRC, the prognosis in a large number of cases remains poor. Therefore, understanding the underlying molecular genesis of CRC is important for precise diagnosis, treatment, and prognosis of the disease. It has been reported that these processes are associated with miRNAs to varying degrees $(52,53)$. The miRNAs of CRC that are modulated by curcumin are summarized in Table II.

Curcumin mediates sensitization to 5-fluorouracil in CRC cells by inhibition of the epithelial-to-mesenchymal transition (EMT) and polycomb repressive complexes (PRCs) via the regulation of certain miRNAs. Specifically, curcumin was shown to upregulate the expression of miR-429, miR-200b, miR-200c, miR-141, and miR-101, whereas 5-fluorouracil did not significantly alter the expression of these miRNAs $(54,55)$.

miR-21 fulfills an important role in cancer development, and curcumin is able to inhibit tumor growth, invasion, and in vivo metastasis by regulating miR-21 in CRC. Furthermore, two novel transcriptional start sites of the miR-21 gene have been identified in HCT116 and Rko cells. Curcumin was shown to significantly reduce miR-21 expression and promoter activity in a dose-dependent manner by inhibiting the binding of activator protein 1 to the promoter. Subsequently, the expression of programmed cell death protein 4 (PDCD4), which is a target of miR-21, was shown to be increased, leading to tumor suppression $(56,57)$.

Previously published in vitro data have indicated that, in CRC cells, curcumin, in combination with 3-acetyl-11-keto$\beta$-boswellic acid (AKBA), downregulated the expression of miR-27a, and upregulated the expression of tumor-suppressive miR-34a. Furthermore, both curcumin and AKBA were shown to markedly decrease tumor growth in a mouse xenograft model, and these effects were identified with alterations in the expression of miR-34a and miR-27a (58).

Paternally expressed gene-10 (PEG10) may be regulated by miR-491 in certain types of cancer. Furthermore, miR-491 regulates the sensitivity of anti-cancer drugs when used to treat CRC. Curcumin was revealed to upregulate miR-491 expression, which suppressed the PEG10 and Wnt/ $\beta$-catenin growth pathways, thereby inhibiting the proliferation of HCT116 cells (59).

Curcumin was also shown to inhibit the growth of RKO and SW480 colon cancer cells and induce apoptosis, as well as downregulate the specificity protein (Sp) transcription factors, $\mathrm{Sp} 1, \mathrm{Sp} 3$, and $\mathrm{Sp} 4$. Therefore, genes regulated by $\mathrm{Sp}$, including those encoding epidermal growth factor receptor, c-MET, survivin, bcl-2, cyclin D1 and nuclear factor- $\kappa \mathrm{B}$, have been shown to be downregulated. The mechanism of curcumin-induced inhibition of $\mathrm{Sp}$ transcription factors is mediated via an increase in the expression of the Sp inhibitors, 
Table III. Curcumin modulates miRNAs in prostate cancer.

\begin{tabular}{|c|c|c|c|c|}
\hline Author, year & Cell line & miRNA & Downstream target(s) & (Refs.) \\
\hline Cao et al, 2017 & DU145 & $\operatorname{miR}-143(\uparrow)$ & PGK1 & $(65)$ \\
\hline Liu et al, 2017 & $\begin{array}{l}\text { PC3 } \\
\text { DU145 } \\
\text { LNCaP }\end{array}$ & $\operatorname{miR}-143(\uparrow)$ & ATG2B & (66) \\
\hline Liu et al, 2017 & $\begin{array}{l}\text { Du145 } \\
22 \mathrm{RV} 1\end{array}$ & $\operatorname{miR}-145(\uparrow)$ & - & (67) \\
\hline Zhang et al, 2018 & $\begin{array}{l}\text { Du145 } \\
\text { 22RV1 }\end{array}$ & $\begin{array}{l}\operatorname{miR}-770-5 p \\
\operatorname{miR}-1247\end{array}$ & - & (68) \\
\hline
\end{tabular}

The upwards and downwards pointing arrows indicate up- and downegulation, respectively. PGK1, phosphoglycerate kinase-1; ATG2B, autophagy related $2 \mathrm{~B}$.

Table IV. Curcumin modulates miRNAs in breast cancer.

\begin{tabular}{llll}
\hline $\begin{array}{l}\text { Author, year } \\
\text { Wang } \text { et al, } 2017\end{array}$ & Cell line & miRNA & Downstream target(s) \\
Li et al, 2014 & MCF-7 & miR-21 $(\downarrow)$ & PTEN/Akt \\
& MCF-7 & $\begin{array}{l}\text { miR-19a }(\downarrow) \\
\text { miR-19b }(\downarrow)\end{array}$ & PTEN/Akt/p53 \\
Yang et al, $2010 ;$ & MCF-7 & miR-15a $(\uparrow)$ & Bcl-2 \\
Norouzi et al, 2018 & miR-16 $(\uparrow)$ & Bcl-2 \\
Guo et al, 2013 & MDA-MB-231 & miR-34a $(\uparrow)$ & Bmi-1 \\
& MDA-MB-435 & & CXCL1 \\
Kronski et al, 2014 & MDA-MB-231 & miR-181b $(\uparrow)$ & CXCL2 \\
\hline
\end{tabular}

The upwards and downwards pointing arrows indicate up- and downegulation, respectively. PTEN, phosphatase and tensin homolog; CXCL1/2, chemokine (C-X-C motif) ligand 1/2.

ZBTB10 and ZBTB4, and the downregulation of miR-27a, miR-20a and miR-17-5p (60). Curcumin has also been shown to inhibit the proliferation of colon cancer cells in a mouse model by suppressing the $\mathrm{Wnt} / \beta$-catenin pathway via inhibition of miR-130a. These results suggested that curcumin may have potential in terms of developing novel therapies to treat CRC (61).

Curcumin and miRNAs in prostate cancer. Annually, approximately 1.1 million men are diagnosed with prostate cancer (62). Moreover, worldwide, prostate cancer is the second most commonly occurring type of cancer. Accumulating data has suggested that miRNAs may be used as predictive, diagnostic, and prognostic biomarkers $(63,64)$. The miRNAs of prostate cancer known to be modulated by curcumin are summarized in Table III.

Curcumin was shown to markedly upregulate miR-143 expression and inhibit the proliferation and migration of prostate cancer cells, which could be blocked by transfection with anti-miR-143. Both miR-143 overexpression and curcumin downregulated the expression of phosphoglycerate kinase-1 (PGK1), which upregulated the protein, forkhead box D3
(FOXD3). Furthermore, the ectopic expression of FOXD3 synergized with curcumin to upregulate the expression of miR-143 (65).

Interestingly, curcumin elicited a radiosensitizing effect in prostate cancer by increasing the expression of miR-143, enhancing apoptosis, and decreasing cancer cell growth induced by radiation. Curcumin was shown to restore the expression of miR-143 in PC3, DU145, and LNCaP prostate cancer cells. Curcumin, similar to the compound 5-A2a-2'-deoxycytidine (5-AZA-dC), was shown to decrease the methylation of $\mathrm{CpG}$ dinucleotides in the miR-143 promoter. In addition, curcumin decreased the expression of DNA (cytosine-5-)-methyltransferase 1 (DNMT1) and DNMT3B, an effect that elicited hypermethylation of the miR-143/miR-145 cluster (66).

Six miRNAs (namely, miR-145, miR-1275, miR-1908, miR-3127, miR-3178, and miR-3198) were shown to be markedly upregulated in human prostate cancer stem cells (HuPCaSCs) incubated with curcumin compared with cells that were incubated with vehicle, or untreated cells. Conversely, eight miRNAs (i.e., miR-671-5p, miR-664*, miR-494, miR-222*, miR-210, miR-193b*, miR-183, and miR-23b*) were markedly downregulated in HuPCaSCs incubated with curcumin (67). 
Table V. Curcumin modulates miRNAs in nasopharyngeal cancer.

\begin{tabular}{llllr}
\hline Author, year & Cell line & \multicolumn{1}{c}{ miRNA } & Downstream target(s) & (Refs.) \\
\hline Gao et al, 2014 & HONE1 & $\begin{array}{l}\text { miR-125a-5p }(\downarrow) \\
\text { miR-574-3p }(\downarrow) \\
\text { miR-210 }(\downarrow)\end{array}$ & TP53 & \\
Feng et al, 2017 & miR-7 $(\uparrow)$ & Skp2 & $(80)$ \\
Fan et al, 2016 & CNE1 2 & miR-593 $(\uparrow)$ & MDR1 & $(81)$ \\
\hline
\end{tabular}

The upwards and downwards pointing arrows indicate up- and downegulation, respectively. TP53, tumor protein 53; Skp2, S-phase kinase-associated protein 2; MDR1, multidrug resistance protein 1.

Curcumin (at a concentration of $46.5 \mu \mathrm{M}$ ) significantly inhibited the proliferation and invasion of HuPCaSCs in vitro. The expression levels of miR-770-5p and miR-1247 in the DLK1-DIO3 imprinted gene cluster were significantly increased in HuPCaSCs incubated with curcumin, compared with cells incubated with vehicle (68).

Curcumin and miRNAs of breast cancer. In the United States, breast cancer is one of the most commonly occurring cancers among females. Molecular profiling of breast cancer has revealed a dysregulation of miRNAs, and miRNAs may be putative diagnostic and prognostic markers in the treatment of breast cancer $(69,70)$. The miRNAs of breast cancer modulated by curcumin are summarized in Table IV.

Curcumin has been shown to attenuate the malignancy of breast cancer cells by inhibiting the miR-21/PTEN/Akt signaling pathway. Curcumin elicited a significant concentrationdependent decrease in the expression level of miR-21 in MCF-7 cells. The overexpression of miR-21 markedly inhibited the anti-cancer efficacy of curcumin in MCF-7 cells by suppressing the expression of PTEN and increasing the expression of the protein, phosphorylated (p-)Akt (71).

In MCF-7 cells, curcumin was shown to reverse bisphenol A (BPA)-induced upregulation of the oncogenic miRNAs, miR-19a, miR-19b, and it also upregulated their downstream targets, including proliferating cell nuclear antigen, p-Akt, p-MDM2, PTEN, and p53 (72). Additional results published in that study suggested that curcumin regulated the miR-19/PTEN/Akt/p53 pathway to reverse BPA-induced breast cancer progression (72). Furthermore, in MCF-7 cells that were incubated with curcumin, curcumin was shown to increase the expression levels of miR-15a and miR-16, resulting in the downregulation of Bcl-2. Additionally, the silencing of miR-15a and miR-16 via specific inhibitors restored the expression of Bcl-2, whereas a decrease in the expression levels of Bcl-2 induced apoptosis of the MCF-7 cells $(73,74)$.

Curcumin and emodin have been shown to produce synergistic effects in breast cancer MDA-MB-435 and MDA-MB-231 cells, which are classified as triple-negative breast cancer cells. Curcumin and emodin increased the expression of miR-34a in breast cancer cells. Curcumin and emodin also significantly inhibited Bcl-2 and Bmi-1 expression in MDA-MB-231 and MDA-MB-435 breast cancer cells, and this decrease could be reversed by a miR-34a inhibitor (75). In MDA-MB-231 cells, curcumin modulated the expression of various miRNAs; for example, miR-181b was upregulated. Interestingly, miR-181b downregulated the levels of the chemokines CXCL1 and CXCL2 by binding to their 3'-UTR. The overexpression of miR-181b led to a marked decrease in the levels of CXCL1 and CXCL2, influencing the efficacy of curcumin on CXCL1 and CXCL2 (76).

Curcumin and miRNAs in nasopharyngeal carcinoma (NPC). The majority of NPC cases (75-90\%) are diagnosed at an advanced stage, which contributes to its high risk of recurrence, and metastasis with poor clinical outcomes. Several miRNAs have been shown to be potential biomarkers and therapeutic targets in NPC $(77,78)$. The miRNAs of NPC known to be modulated by curcumin are summarized in Table V.

RT-qPCR and miRNA microarray analysis suggested that curcumin decreases the expression levels of miR-574-3p, miR-210, and miR-125a-5p in NPC cells. The overexpression of miR-125a-5p facilitated the proliferation, migration, and invasion of HONE1 cancer cells. Moreover, curcumin increased the expression of tumor protein 53 (TP53), a downstream target of miR-125a-5p (79). Curcumin has been shown to inhibit the growth, migration, and invasion of human NPC CNE1 and CNE2 cells by inducing cell cycle arrest and apoptosis following irradiation. Curcumin was shown to increase the expression of miR-7, which inhibits the expression of its direct target, S-phase kinase-associated protein 2 (Skp2) (80). Curcumin, in combination with 4 Gy irradiation, inhibited the proliferation of transplanted tumors in vivo, producing a greater efficacy of curcumin compared with radiotherapy treatment alone. The upregulation of miR-593 mediated by curcumin led to a decrease inexpression of multidrug resistance 1 protein (MDR1), a downstream target of miR-593 (81).

Curcumin and miRNAs in pancreatic cancer. The diagnosis and treatment of pancreatic cancer remains a major clinical challenge. Due to the nature of early metastasis, at least $80 \%$ of patients with pancreatic cancer have an invasive lesion upon diagnosis (82). Thus, surgical and medical interventions for pancreatic cancer are fundamentally unsuccessful, resulting in high mortality rates and a poor clinical prognosis. It has been hypothesized that there is a correlation between 
Table VI. Curcumin modulates miRNAs in pancreatic cancer.

\begin{tabular}{llll}
\hline Author, year & Cell line & miRNA & Downstream target(s) \\
\hline Yang et al, 2017 & PANC-1 & miR-340 $(\uparrow)$ & XIAP \\
Ma et al, 2014 & AsPC-1 & miR-7 $(\uparrow)$ & SET8 \\
Sun et al, 2008 & BxPC-3 & & SP1 \\
& BxPC-3 & miR-22 $(\uparrow)$ & ESR1 \\
\hline
\end{tabular}

The upwards and downwards pointing arrows indicate up- and downregulation, respectively. XIAP, X-linked inhibitor of apoptosis; SET8, SET domain-containing lysine methyltransferase 8; SP1, specificity protein 1; ESR1, estrogen receptor 1.

Table VII. Curcumin modulates miRNAs in leukemia.

\begin{tabular}{llll}
\hline Author, year & Cell line & miRNA & Downstream target(s) \\
\hline Taverna et al, 2016; & K562 & miR-21 $(\downarrow)$ & PTEN \\
Taverna et al, 2015 & LAMA84 & miR-196b $(\uparrow)$ & Bcr-Abl \\
Gao et al, 2012 & K562 & miR-15a $(\uparrow)$ & WT1 \\
& HL-60 & miR-16-1 $(\uparrow)$ & \\
\hline
\end{tabular}

The upwards and downwards pointing arrows indicate up- and downegulation, respectively. PTEN, phosphatase and tensin homolog; WT1, Wilms' tumor 1.

altered miRNA expression and pancreatic cancer $(83,84)$. The miRNAs of pancreatic cancer modulated by curcumin are summarized in Table VI.

Previously published data have suggested that curcumininduced apoptosis is associated with the miR-340/X-linked inhibitor of apoptosis (XIAP) signaling pathway in PANC-1 pancreatic cancer cells. In addition, incubation with curcumin or miR-340 induced apoptosis of pancreatic cancer cells, whereas silencing the endogenous miR-340 significantly decreased the apoptotic efficacy of curcumin. Western blotting and luciferase reporter assays revealed that the oncogene, XIAP, is a direct downstream target of miR-340. Furthermore, curcumin led to a significant decrease in the expression of XIAP, a phenomenon that was reversed by anti-miR-340 (85).

In the pancreatic cancer cell lines, BxPC-3 and AsPC-1, curcumin has been shown to inhibit cell proliferation, migration, and invasion, and to induce apoptosis. These effects were correlated with an increase in the expression of miR-7 and subsequent downregulation of SET domain-containing lysine methyltransferase 8 (SET8), a downstream target of miR-7. These results suggested that miR-7 is modulated by curcumin, and that this may represent a novel therapeutic strategy for the treatment of pancreatic cancer (86).

In addition, curcumin has been shown to modulate miRNA expression of BxPC-3 human pancreatic cancer cells, downregulating miRNA-199a* and upregulating miR-22. Upregulation of miR-22 by curcumin, or transfection with miR-22 mimics in BxPC-3 cells, was shown to suppress the expression of downstream target genes, namely the transcription factor $\mathrm{Sp} 1$ and estrogen receptor 1 (87).
Curcumin and miRNAs of leukemia. Globally, leukemia accounts for approximately $2.5 \%$ of all new cancer cases, and $3.5 \%$ of all cancer-associated deaths (88). Chronic myeloid leukemia (CML), an acquired malignant disorder of hematopoietic stem cells, is one of three common types of leukemia. Similarly to solid cancers, it has been reported that miRNAs are dysregulated in hematological malignancies $(89,90)$. The miRNAs of leukemia modulated by curcumin are summarized in Table VII.

The incubation of CML K562 and LAMA84 cells with curcumin (at concentrations of 10, 20 and $40 \mu \mathrm{M}$ ) was found to produce a concentration-dependent upregulation of PTEN, one of the targets of miR-21. Curcumin, in vitro, decreased the expression of vascular endothelial growth factor and the phosphorylation of Akt. Colony formation experiments indicated that curcumin inhibits the viability of CML cells. Curcumin also decreased the expression of miR-21 in CML cells, and the secretion of exosomes. Furthermore, curcumin was shown to increase the expression of miR-196b, which regulates the CML-associated protein Bcr-Abl $(91,92)$.

Curcumin-mediated overexpression of miR-15a and miR-16-1 occurs prior to the downregulation of the protein, Wilms' tumor 1 (WT1). Furthermore, anti-miR-15a and anti-miR-16-1 oligonucleotides are able to partially restore the decreased expression of WT1 mediated by curcumin in leukemic K562 and HL-60 cells. In addition, anti-miR-15a/16-1 oligonucleotides increased the proliferation of K562 and HL-60 cells that is elicited by curcumin (93).

Curcumin and miRNAs in ovarian cancer. Ovarian cancer is typically diagnosed at an advanced stage without symptoms, 
Table VIII. Curcumin modulates miRNAs in ovarian cancer.

\begin{tabular}{llll}
\hline Author, year & Cell line & miRNA & Downstream target(s) \\
\hline Zhang et al, 2017 & OVCAR-3 & miR-214 $(\downarrow)$ & MEG3 \\
& SKOV3 & & \\
& A2780cp & & \\
A2780 & & Midkine \\
Zhao et al, 2017 & SKOV3 & miR-124 $(\uparrow)$ & p-Akt \\
Zhao et al, 2014 & SKOV3 & miR-9 $(\uparrow)$ & p-FOXO1 \\
\hline
\end{tabular}

The upwards and downwards pointing arrows indicate up- and downegulation, respectively.p-, phosphorylated; MEG3, maternally expressed 3; FOXO3, forkhead Box D3.

thereby making it difficult to treat. Emerging data have shown that miRNAs elicit oncogenesis or activate tumor suppressors in ovarian tumors $(94,95)$. The miRNAs of ovarian cancer modulated by curcumin are summarized in Table VIII.

miR-214 significantly modulates the effects of chemotherapy in ovarian cancer. In vitro, miR-214 has been shown to affect cisplatin resistance and cell survival by regulating the PTEN/Akt signaling pathway. Furthermore, miR-214 induced stem cell properties by interacting with the p53/Nanog pathway in ovarian cancer. Curcumin was shown to decrease miR-214 expression, which, in turn, led to a decrease in cisplatin resistance in OVCAR-3 and SKOV3 cells (96).

In SKOV3 cells, the combination of dihydroartemisinin and curcumin has been shown to synergistically inhibit cell growth and induce cell cycle arrest and apoptosis. Moreover, this led to a marked decrease in the expression of the oncogene, midkine, and synergistically increased the expression of miR-124. Furthermore, miR-124 was shown to directly bind to the 3'-UTR of midkine mRNA, causing its degradation, thereby decreasing the expression of the midkine protein (97).

In addition, curcumin significantly inhibits the proliferation of SKOV3 cells and elicits apoptosis, increasing the expression of miR-9. The depletion of miR-9 attenuated the anti-cancer efficacy of curcumin, whereas its overexpression increases the levels of apoptosis in SKOV3 cells. Overexpression of miR-9 and curcumin led to a marked decrease in the levels of p-Akt and p-FOXO1 compared with cells incubated with vehicle (98).

Curcumin and miRNAs in other cancers. Dendrosomal curcumin has been shown to potently inhibit the proliferation of U87MG cells by i) arresting the cell cycle during the $\mathrm{G}_{1}$ phase; and ii) inducing apoptosis. Dendrosomal curcumin significantly increased the expression of miR-145, leading to the subsequent downregulation of its downstream proteins, including octamer-binding transcription factor 4A (OCT4A), OCT4B1, (sex determining region Y)-box 2 (SOX-2), and Nanog (99). Curcumin significantly reduces the expression of miR-222, miR-221, miR-146b, and miR-21 in SW1736 and
8505C cells. Furthermore, the abovementioned miRNAs, as well as miR-204, were shown to mediate the efficacy of nutraceuticals in thyroid cancer progression (100).

The expression level of miR-9 in oral squamous cell carcinoma is lower compared with that in the adjacent non-tumor tissue. Curcumin has been shown to inhibit the cell growth of SCC-9 oral squamous cell carcinoma cells by increasing the expression levels of miR-9 and disrupting the $\mathrm{Wnt} / \beta$-catenin pathway. Specifically, the expression levels of glycogen synthase kinase-3 $\beta$ (GSK-3 $\beta$ ), p-GSK-3 $\beta$ and $\beta$-catenin were increased, whereas that of cyclin D1 was decreased (34).

Clinically, the expression of the tumor suppressor, miR-203, is epigenetically downregulated in bladder cancer. Curcumin upregulates miR-203 expression in TCCSUP, T24, and J82 bladder cancer cells by producing DNA hypomethylation of the miR-203 promoter. The overexpression of miR-203 downregulated the target oncogenes Akt2/Src, thereby decreasing cell survival, migration, and invasion (101).

A nanoparticle formulation of curcumin (Nano-CUR), based on polylactic-co-glycolic acid, was developed and tested in cervical cancer cells in vitro and in a pre-clinical orthotopic mouse model. Nano-CUR has been shown to significantly suppress cell proliferation, induce apoptosis, cause cell cycle arrest in the cervical cancer cell lines $\mathrm{Ca}$ Ski and Si Ha, downregulate the expression of oncogenic miRNA-21, repress $\beta$-catenin levels in the nucleus, and decrease the expression level of the oncoprotein, E6/E7 HPV. Furthermore, miRNA-21 decreased the expression of E6/E7 and interleukin-6, whose levels are increased by benzo[a]pyrene (102).

In U2OS and MG63 osteosarcoma cells, curcumin was shown to significantly suppress the expression of estrogen-related receptor- $\alpha$ (ERR $\alpha$ ) by upregulating miR-125a. The overexpression of ERR $\alpha$ decreased the induction of apoptosis mediated by curcumin, whereas silencing ERR $\alpha$ led to a sensitization of the osteosarcoma cells to curcumin (103). By contrast, curcumin inhibited miR-125a expression in undifferentiated NPC cells (79). The differing tumor characteristics may be a factor underlying the contrasting effects produced by curcumin in regulating miR-125a.

Curcumin has been shown to repress cell growth, increase caspase- 3 activity, and stimulate apoptosis in the laryngeal squamous cell carcinoma cell line, AMC-HN-8. Curcumin 


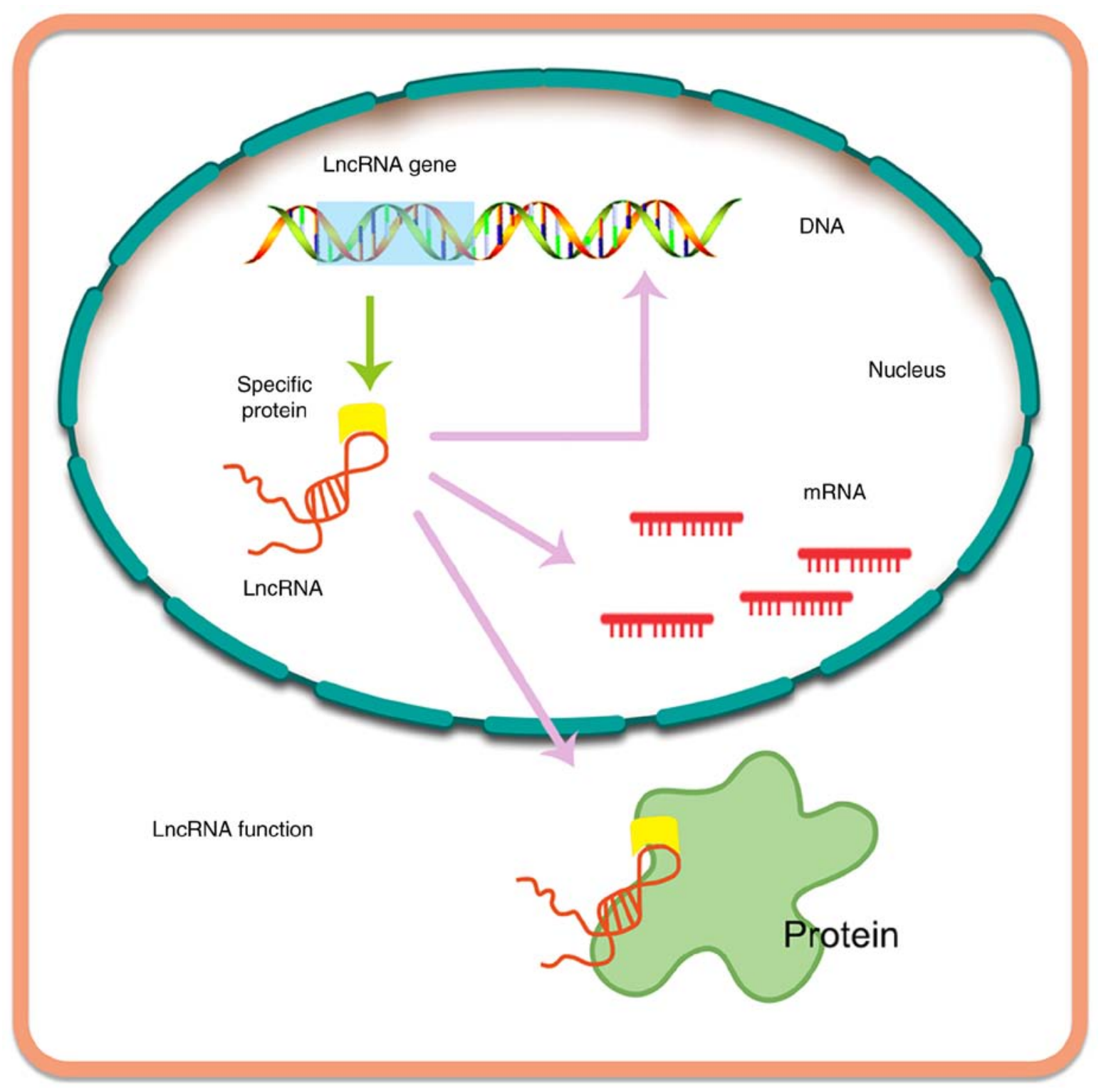

Figure 5. Biogenesis of lncRNA and its function. lncRNA, long non-coding RNA.

increased miR-15a expression, and downregulated the protein levels of Bcl-2, PI3K, and p-Akt. The suppression of miR-15a is able to reverse the anti-proliferative efficacy of curcumin and increase the expression levels of Bcl-2 and PI3K/Akt in AMC-HN-8 cells (104).

\section{Curcumin regulates cancer IncRNAs}

Biogenesis and function of IncRNAs. IncRNAs are byproducts of transcription, typically consisting of $>200$ bases (105). lncRNAs are primarily transcribed by the enzymes RNA polymerase II and RNA polymerase III $(19,106)$. Similarly to miRNAs, lncRNAs are also able to bind to certain proteins, RNA and nucleating RNA compartments, forming ribonucleoprotein complexes. Interestingly, lncRNAs can function immediately after synthesis, acting as flexible scaffolds to promote dynamic gene control (107). Recently, a number of studies have reported the potential role of IncRNAs in normal and pathological processes [e.g., see (20)]. Furthermore, it has been demonstrated that the expression of thousands of IncRNAs varies according to the types of tumor, and certain of these have been linked to tumorigenesis $(19,108)$.

Currently, a total of 7,258 sncRNAs and 15,767 annotated IncRNAs have been recorded in the GENCODE database, which contains the largest known compilation of transcripts $(20,109)$. IncRNAs are able to modulate multiple levels of gene expression (Fig. 5), including regulation at the epigenetic, transcriptional, and post-transcriptional levels, based on the findings of tissue microarray analyses and next-generation sequencing assays. Thus, in the future, lncRNAs may attract interest in various therapeutic areas.

IncRNAs can act as sponges or molecular decoys of miRNAs, influencing the expression and activities of miRNAs (65). Furthermore, miRNAs could directly or indirectly target lncRNAs. Accumulating evidence has suggested that an active crosstalk between IncRNAs and miRNA exists via a double-negative feedback circle that is able to manipulate the levels of gene expression (108). 


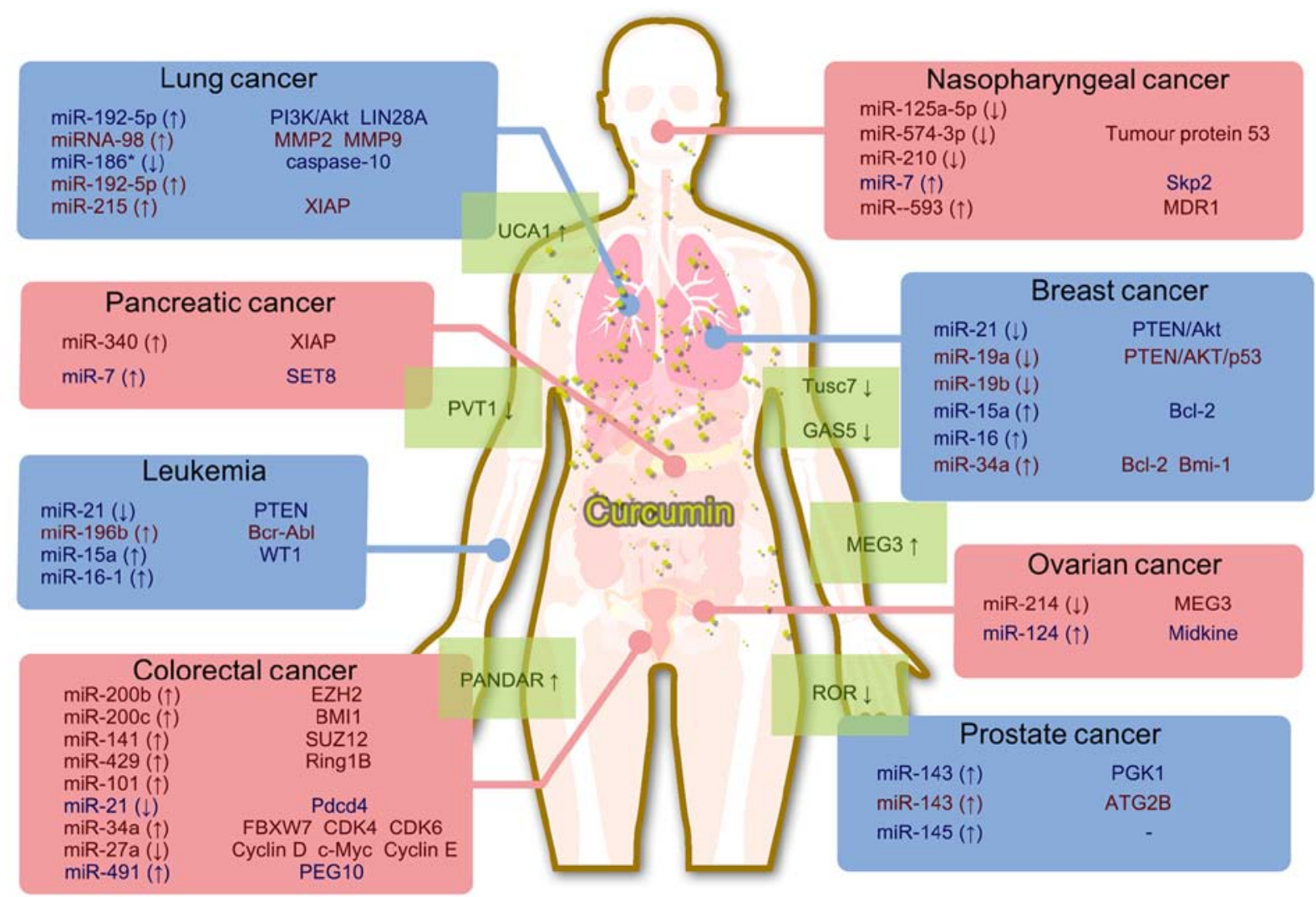

Figure 6. Summary of the mechanism by which curcumin targets miRNAs and lncRNAs.

Curcumin regulates IncRNAs in lung cancer. IncRNAs participate in epigenetic regulation, transcriptional regulation, and post-transcriptional processing. There are two major categories of IncRNAs, which are defined as oncogene lncRNAs [metastasis-associated lung adenocarcinoma transcript 1 (MALAT1), HOX transcript antisense RNA (HOTAIR), SOX2 overlapping transcript (SOX2-OT), H19, etc.] and tumor suppressor lncRNAs [maternally expressed 3 (MEG3), promoter of CDKN1A antisense DNA damage-activated RNA (PANDAR), growth arrest-specific 5 (GAS5), taurine-upregulated gene 1 (TUG1), etc.], according to their pathological features (110). Therefore, numerous dysregulated lncRNAs have been identified in patients with NSCLC as specific biomarkers for diagnosis. The upregulation of 24 lncRNAs (MALAT1, HOTAIR, H19, etc.) and downregulation of 9 lncRNAs (GAS5, PANDAR, MEG3, etc.) have been observed in NSCLC (111).

Furthermore, mechanistic studies have revealed that curcumin is able to inhibit the growth of A549 cells and the expression of urothelial cancer associated-1 (UCA1), the overexpression of which abolished the effect of curcumin on cell apoptosis. Subsequently, curcumin may inhibit the Wnt and mTOR pathways by downregulating UCA1, which could provide novel insights into the treatment of lung cancer (112).

Curcumin regulates IncRNA in CRC. CRC-associated lncRNAs are involved in invasion, metastasis, chemoresistance and radioresistance by interactions with different signalling pathways, including the EMT, Wnt, and transforming growth factor- $\beta$ (TGF- $\beta$ ) pathways, and also interactions with miRNAs (113). Specifically, accumulating evidence has indicated that lncRNAs are able to directly modulate metastatic pathways in CRC. A total of 28 CRC-associated oncogene lncRNAs (HOTAIR, UCA1, H19, MEG3, etc.) were identified in a recent study, and 13 tumor suppressor lncRNAs (MEG3, GAS5, etc.) (114).

Experiments in vitro have indicated that knockdown of PANDAR lncRNA did not significantly affect proliferation, senescence, or apoptosis of CRC cells. It has been reported that curcumin produces senescence of CRC cells without increasing apoptosis. Furthermore, PANDAR expression was upregulated in CRC cells incubated with curcumin. The silencing of PANDAR increased the rate of apoptosis and significantly decreased the level of senescence, results that are likely to be accounted for by increasing the levels of p53-upregulated modulator of apoptosis (PUMA) in CRC cells incubated with curcumin (115).

Curcumin regulates IncRNA in prostate cancer. Compared with normal tissues, distinct fold changes of $60-100$ for $95 \%$ of prostate tumors were detected; therefore, prostate cancer antigen-3 (PCA3) can be potentially applied as a specific prostate cancer biomarker, which is undetectable in other tumor types (116). It was reported that 17 lncRNAs (HOTAIR, SOCS2-AS1, PVT1, etc.) contribute to prostate cancer progression. Additionally, low expression levels of $3 \mathrm{lncRNAs}$ (GAS5, MEG3, and H19) were detected in prostate cancer (117).

In vitro, $\mathrm{HuPCaSCs}$ with overexpression of miR-145, cell cycle arrest and inhibition of cell proliferation and invasion were observed following pre-treatment with curcumin. Luciferase activity assays revealed that Oct 4 and lncRNA-ROR 
are able to bind to miRNAs competitively via their common binding sites of miR-145. In general, downregulation of endogenous lncRNA-ROR increased expression of miR-145 in HuPCaSCs; subsequently, miR-145 inhibited cell proliferation by decreasing Oct4 expression (67).

Curcumin regulates IncRNA in breast cancer. Some lncRNAs have particular associations with specific types of cancer. For example, in the case of breast cancer, several lncRNAs (HOTAIR, MALAT1, H19, etc.) are associated with cancer progression (118).

Dendrosomal curcumin treatment in MCF7, MDA-MB231 and SKBR3 cells has been shown to reduce the expression of Tusc7 and GAS5 1ncRNAs. GAS5 downregulation leads to an enhancement of the anticancer effect of dendrosomal curcumin. It appears that a combination of dendrosomal curcumin and GAS5 overexpression may be applied as a therapy for drug-resistant breast cancer in the clinic (119).

Curcumin regulates IncRNA in pancreatic cancer. Increases in the expression of the IncRNAs ROR, H19, nuclear-enriched abundant transcript-1 (NEAT1), nuclear transport factor 2 pseudogene 3 (NUTF2P3), and MIR31HG were identified in pancreatic cancer via different mechanisms (120). In addition, overexpression of 7 lncRNAs (ROR, H19, NEAT1, etc.) was observed in pancreatic cancer, whereas that of only one lncRNA (ENST00000480739) was shown to be decreased in a recently published study (121). Curcumin treatment in BxPC3-GemR cells promoted a reversal of gemcitabine resistance by inhibiting the expression of the PRC2 subunit, EZH2, and its associated lncRNA, PVT1 (122).

Curcumin regulates IncRNA in ovarian cancer. Various novel methods, including RT-qPCR and high-throughput techniques, have been applied to build up the lncRNA expression profile for ovarian cancer. Furthermore, IncRNA clusters show distinct metastatic potentials with different expression levels in ovarian cancer cells (123). For example, lncRNA MEG3 has been shown to be efficacious as a cancer suppressor. Curcumin increases the expression of MEG3 in ovarian cancer. A mechanistic study revealed that DNA hypomethylation maybe induced by dendrosomal curcumin, which resulted in the re-expression of silenced tumor suppressor genes, such as MEG3 (96).

\section{Conclusions and perspectives}

Non-coding RNAs have been shown to exert critical roles in regulating cancer cell biology, and they may serve as promising targets for novel anti-cancer treatments. The natural product curcumin has been demonstrated to possess significant anti-proliferative efficacy in different types of cancer cell. The known effects of curcumin that have been established with respect to miRNA/lncRNA expression are summarized in Fig. 6. It is possible that curcumin inhibits cancer cell proliferation by regulating certain non-coding RNAs, which are important for cancer cell proliferation. These findings will help to elucidate the mechanisms that underpin the efficacy of curcumin, thereby providing valuable information for the evaluation of novel cancer treatments.

\section{Acknowledgements}

We thank Yangmin Chen, who provided editorial assistance.

\section{Funding}

This work was supported by National Natural Science Foundation of China (grant nos. 81473320 and 81773888), Fund of Guangdong Science and Technology Department (grant no. 2016A020226024), Fund of Guangzhou Science and Technology Program (grant no. 201707010048), Fund of Guangdong Education Department (grant no. 2015KTSCX112), the Fund of Construction of High-Level Universities in Guangdong (Nanshan Scholars Program and Academic Backbone Program), and Fund of Xinjiang Science and Technology Department (grant nos. 2013711020 and 201223111).

\section{Availability of data and materials}

Not applicable.

\section{Authors' contributions}

JZ and ZC conceived the review; YL, HS, QC, JL, and CS wrote the review. BM, CRA Jr, ZC, and JZ revised the review. All authors read and approved the final manuscript.

\section{Ethics approval and consent to participate}

Not applicable.

\section{Patient consent for publication}

Not applicable.

\section{Competing interests}

The authors declare that they have no competing interests.

\section{References}

1. Shi Z, Li Z, Li ZJ, Cheng K, Du Y, Fu H and Khuri FR: Cables1 controls $\mathrm{p} 21 / \mathrm{Cip} 1$ protein stability by antagonizing proteasome subunit alpha type 3. Oncogene 34: 2538-2545, 2015.

2. Jiang QW, Cheng KJ, Mei XL, Qiu JG, Zhang WJ, Xue YQ, Qin WM, Yang Y, Zheng DW, Chen Y, et al: Synergistic anticancer effects of triptolide and celastrol, two main compounds from thunder god vine. Oncotarget 6: 32790-32804, 2015.

3. Zhang JY, Wu HY, Xia XK, Liang YJ, Yan YY, She ZG, Lin $\mathrm{YC}$ and $\mathrm{Fu}$ LW: Anthracenedione derivative 1403P-3 induces apoptosis in KB and KBv200 cells via reactive oxygen species-independent mitochondrial pathway and death receptor pathway. Cancer Biol Ther 6: 1413-1421, 2007.

4. Zhang JY, Tao LY, Liang YJ, Yan YY, Dai CL, Xia XK She ZG, Lin YC and Fu LW: Secalonic acid D induced leukemia cell apoptosis and cell cycle arrest of G(1) with involvement of GSK-3beta/beta-catenin/c-Myc pathway. Cell Cycle 8: 2444-2450, 2009.

5. Zhang JY, Huang WJ, Sun HM, Liu Y,Zhao XQ, Tang SL, Sun MN Wang S, Li JJ, Zhang LL, et al: Structure identification and in vitro anticancer activity of lathyrol-3-phenylacetate-5,15-diacetate. Molecules 22: e1412, 2017.

6. Zhang J, Lai Z, Huang W, Ling H, Lin M, Tang S, Liu Y and Tao Y: Apicidin inhibited proliferation and invasion and induced apoptosis via mitochondrial pathway in non-small cell lung cancer GLC-82 cells. Anticancer Agents Med Chem 17: 1374-1382, 2017. 
7. Shi Z, Peng XX, Kim IW, Shukla S, Si QS, Robey RW, Bates SE Shen T, Ashby CR Jr, Fu LW, et al: Erlotinib (Tarceva, OSI-774) antagonizes ATP-binding cassette subfamily B member 1 and ATP-binding cassette subfamily $\mathrm{G}$ member 2-mediated drug resistance. Cancer Res 67: 11012-11020, 2007.

8. Zhang JY, Mi YJ, Chen SP, Wang F, Liang YJ, Zheng LS, Shi CJ, Tao LY, Chen LM, Chen HB and Fu LW: Euphorbia factor L1 reverses $\mathrm{ABCB} 1-$ mediated multidrug resistance involving interaction with $\mathrm{ABCB} 1$ independent of $\mathrm{ABCB} 1$ downregualtion. J Cell Biochem 112: 1076-1083, 2011.

9. Lin M, Bi H, Yan Y, Huang W, Zhang G, Zhang G, Tang S, Liu Y, Zhang L, Ma J and Zhang J: Parthenolide suppresses non-small cell lung cancer GLC-82 cells growth via B-Raf/MAPK/Erk pathway. Oncotarget 8: 23436-23447, 2017.

10. McLoughlin NM, Mueller C and Grossmann TN: The therapeutic potential of PTEN modulation: Targeting strategies from gene to protein. Cell Chem Biol 25: 19-29, 2018.

11. Zhang JY, Lin MT, Tung HY, Tang SL, Yi T, Zhang YZ, Tang YN, Zhao ZZ and Chen HB: Bruceine D induces apoptosis in human chronic myeloid leukemia K562 cells via mitochondrial pathway. Am J Cancer Res 6: 819-826, 2016.

12. Zhang JY, Tao LY, Liang YJ, Chen LM, Mi YJ, Zheng LS, Wang F, She ZG, Lin YC, To KK and Fu LW: Anthracenedione derivatives as anticancer agents isolated from secondary metabolites of the mangrove endophytic fungi. Mar Drugs 8: 1469-1481, 2010.

13. Yang D, Sun Y,Hu L, Zheng H, Ji P, Pecot CV, Zhao Y, Reynolds S, Cheng H, Rupaimoole R, et al: Integrated analyses identify a master microRNA regulatory network for the mesenchyma subtype in serous ovarian cancer. Cancer cell 23: 186-199, 2013.

14. Tao YW, Lin YC, She ZG, Lin MT, Chen PX and Zhang JY Anticancer activity and mechanism investigation of beauvericin isolated from secondary metabolites of the mangrove endophytic fungi. Anticancer Agents Med Chem 15: 258-266, 2015

15. Zhang JY, Lin MT, Zhou MJ, Yi T, Tang YN, Tang SL, Yang ZJ, Zhao ZZ and Chen HB: Combinational treatment of curcumin and quercetin against gastric cancer MGC-803 cells in vitro. Molecules 20: 11524-11534, 2015

16. Su J, Zhou X, Wang L, Yin X and Wang Z: Curcumin inhibits cell growth and invasion and induces apoptosis through down-regulation of Skp2 in pancreatic cancer cells. Am J Cancer Res 6: 1949-1962, 2016

17. Sharma V and Pathak K: Effect of hydrogen bond formation/replacement on solubility characteristics, gastric permeation and pharmacokinetics of curcumin by application of powder solution technology. Acta Pharm Sin B 6: 600-613, 2016.

18. Fan Y, Liu Y, Zhang L, Cai F, Zhu L and Xu J: C0818, a novel curcumin derivative, interacts with $\mathrm{Hsp} 90$ and inhibits Hsp90 ATPase activity. Acta Pharm Sin B 7: 91-96, 2017.

19. Bian EB, Xiong ZG and Li J: New advances of lncRNAs in liver fibrosis, with specific focus on lncRNA-miRNA interactions. J Cell Physiol 234: 2194-2203, 2019.

20. Castro-Oropeza R, Melendez-Zajgla J, Maldonado V and Vazquez-Santillan K: The emerging role of lncRNAs in the regulation of cancer stem cells. Cell Oncol (Dordr) 41: 585-603, 2018.

21. An X, Sarmiento C, Tan T and Zhu H: Regulation of multidrug resistance by microRNAs in anti-cancer therapy. Acta Pharm Sin B 7: 38-51, 2017.

22. Ferrajoli A, Ivan C, Ciccone M, Shimizu M, Kita Y, Ohtsuka M, D'Abundo L, Qiang J, Lerner S, Nouraee N, et al: Epstein-Barr virus microRNAs are expressed in patients with chronic lymphocytic leukemia and correlate with overall survival. EBioMedicine 2: 572-582, 2015

23. Gong C, Tan W, Chen K, You N, Zhu S, Liang G, Xie X, Li Q, Zeng Y, Ouyang N, et al: Prognostic value of a BCSC-associated microrna signature in hormone receptor-positive HER2-negative breast cancer. EBioMedicine 11: 199-209, 2016.

24. Stark MS, Klein K, Weide B, Haydu LE, Pflugfelder A, Tang YH, Palmer JM, Whiteman DC, Scolyer RA, Mann GJ, et al: The prognostic and predictive value of melanoma-related microRNAs using tissue and serum: A microRNA expression analysis. EBioMedicine 2: 671-680, 2015

25. Montani F and Bianchi F: Circulating cancer biomarkers: The macro-revolution of the micro-RNA. EBioMedicine 5: 4-6, 2016

26. Shah MY, Ferrajoli A, Sood AK, Lopez-Berestein G and Calin GA: microRNA therapeutics in cancer-an emerging concept. EBioMedicine 12: 34-42, 2016.

27. Dou Z, Lin S, Dai C, Lu Y, Tian T, Wang M, Liu X, Zheng Y, Xu P, $\mathrm{Li}$ S, et al: Pooling-analysis for diagnostic and prognostic value of miRNA-100 in various cancers. Oncotarget 8: 62703-62715, 2017.
28. Feng X, Wang Z, Fillmore R and Xi Y: miR-200, a new star miRNA in human cancer. Cancer Lett 344: 166-173, 2014.

29. McGuire A, Brown JA and Kerin MJ: Metastatic breast cancer: The potential of miRNA for diagnosis and treatment monitoring. Cancer Metastasis Rev 34: 145-155, 2015.

30. Huang J, Lyu H, Wang J and Liu B: MicroRNA regulation and therapeutic targeting of survivin in cancer. Am J Cancer Res 5: 20-31, 2014

31. Bobbili MR,Mader RM, Grillari J and Dellago H: OncomiR-17-5p: Alarm signal in cancer? Oncotarget 8: 71206-71222, 2017.

32. Yates LA, Norbury CJ and Gilbert RJ: The long and short of microRNA. Cell 153: 516-519, 2013.

33. Mendell JT and Olson EN: MicroRNAs in stress signaling and human disease. Cell 148: 1172-1187, 2012.

34. Xiao C, Wang L, Zhu L, Zhang C and Zhou J: Curcumin inhibits oral squamous cell carcinoma SCC-9 cells proliferation by regulating miR-9 expression. Biochem Biophys Res Commun 454: 576-580, 2014

35. Rupaimoole R, Calin GA, Lopez-Berestein G and Sood AK: miRNA deregulation in cancer cells and the tumor microenvironment. Cancer Discov 6: 235-246, 2016.

36. Desgagné V, Guérin R, Guay SP, Corbin F, Couture P, Lamarche B and Bouchard L: Changes in high-density lipoprotein-carried miRNA contribution to the plasmatic pool after consumption of dietary trans fat in healthy men. Epigenomics 9: 669-688, 2017.

37. Munoz JL, Bliss SA, Greco SJ, Ramkissoon SH, Ligon KL and Rameshwar P: Delivery of functional anti-miR-9 by mesenchymal stem cell-derived exosomes to glioblastoma multiforme cells conferred chemosensitivity. Mol Ther Nucleic Acids 2: e126, 2013.

38. Calin GA, Dumitru CD, Shimizu M, Bichi R, Zupo S, Noch E, Aldler H, Rattan S, Keating M, Rai K, et al: Frequent deletions and down-regulation of micro-RNA genes miR15 and miR16 at 13 q14 in chronic lymphocytic leukemia. Proc Natl Acad Sci USA 99: 15524-15529, 2002.

39. Mirzaei H, Masoudifar A, Sahebkar A, Zare N, Sadri Nahand J, Rashidi B, Mehrabian E, Mohammadi M, Mirzaei HR and Jaafari MR: MicroRNA: A novel target of curcumin in cancer therapy. J Cell Physiol 233: 3004-3015, 2018

40. Roointan A, Ahmad Mir T, Ibrahim Wani S, Mati-Ur-Rehman, Hussain KK, Ahmed B, Abrahim S, Savardashtaki A, Gandomani G, Gandomani M, et al: Early detection of lung cancer biomarkers through biosensor technology: A review. J Pharm Biomed Anal 164: 93-103, 2019.

41. Lin M, Tang S, Zhang C, Chen H, Huang W, Liu Y and Zhang J: Euphorbia factor L2 induces apoptosis in A549 cells through the mitochondrial pathway. Acta Pharm Sin B 7: 59-64, 2017.

42. Inamura K: Diagnostic and therapeutic potential of microRNAs in lung cancer. Cancers (Basel) 9: E49, 2017.

43. Mehta A, Dobersch S, Romero-Olmedo AJ and Barreto G: Epigenetics in lung cancer diagnosis and therapy. Cancer Metastasis Rev 34: 229-241, 2015.

44. MacDonagh L, Gray SG, Finn SP, Cuffe S, O'Byrne KJ and Barr MP: The emerging role of microRNAs in resistance to lung cancer treatments. Cancer Treat Rev 41: 160-169, 2015.

45. Jin H, Qiao F, Wang Y, Xu Y and Shang Y: Curcumin inhibits cell proliferation and induces apoptosis of human non-small cell lung cancer cells through the upregulation of miR-192-5p and suppression of PI3K/Akt signaling pathway. Oncol Rep 34: 2782-2789, 2015.

46. Liu WL, Chang JM, Chong IW, Hung YL, Chen YH, Huang WT, Kuo HF, Hsieh CC and Liu PL: Curcumin inhibits lin-28A through the activation of miRNA-98 in the lung cancer cell line A549. Molecules 22: E929, 2017.

47. Zhang J, Zhang T, Ti X, Shi J, Wu C, Ren $\mathrm{X}$ and $\mathrm{Yin} H$ Curcumin promotes apoptosis in A549/DDP multidrug-resistant human lung adenocarcinoma cells through an miRNA signaling pathway. Biochem Biophys Res Commun 399: 1-6, 2010.

48. Ye M, Zhang J, Zhang J, Miao Q, Yao L and Zhang J: Curcumin promotes apoptosis by activating the p53-miR-192-5p/215-XIAP pathway in non-small cell lung cancer. Cancer Lett 357: 196-205, 2015.

49. Zhan JW, Jiao DM, Wang Y, Song J, Wu JH, Wu LJ, Chen QY and Ma SL: Integrated microRNA and gene expression profiling reveals the crucial miRNAs in curcumin anti-lung cancer cell invasion. Thorac Cancer 8: 461-470, 2017.

50. Wu GQ, Chai KQ, Zhu XM, Jiang H, Wang X, Xue Q, Zheng AH, Zhou HY, Chen Y, Chen XC, et al: Anti-cancer effects of curcumin on lung cancer through the inhibition of EZH2 and NOTCH1. Oncotarget 7: 26535-26550, 2016. 
51. Zhang $\mathrm{W}$, Bai $\mathrm{W}$ and Zhang $\mathrm{W}$ : miR-21 suppresses the anticancer activities of curcumin by targeting PTEN gene in human non-smal cell lung cancer A549 cells. Clin Transl Oncol 16: 708-713, 2014.

52. Xuan Y, Yang H, Zhao L, Lau WB, Lau B, Ren N, Hu Y, Yi T, Zhao X, Zhou S and Wei Y: MicroRNAs in colorectal cancer: Small molecules with big functions. Cancer Lett 360: 89-105, 2015.

53. Okugawa Y, Grady WM and Goel A: Epigenetic alterations in colorectal cancer: Emerging biomarkers. Gastroenterology 149 1204-1225, 2015.

54. Toden S, Okugawa Y, Jascur T, Wodarz D, Komarova NL, Buhrmann C, Shakibaei M, Boland CR and Goel A: Curcumin mediates chemosensitization to 5-fluorouracil through miRNA-induced suppression of epithelial-to-mesenchymal transition in chemoresistant colorectal cancer. Carcinogenesis 36: 355-367, 2015.

55. Goel A: Utilizing biomarkers in colorectal cancer: An interview with Ajay Goel. Future Oncol 13: 2511-2514, 2017.

56. Mudduluru G, George-William JN, Muppala S, Asangani IA Kumarswamy R, Nelson LD and Allgayer H: Curcumin regulates miR-21 expression and inhibits invasion and metastasis in colorectal cancer. Biosci Rep 31: 185-197, 2011.

57. Riaz Rajoka MS, Jin M, Haobin Z, Li Q, Shao D, Huang Q and Shi J: Impact of dietary compounds on cancer-related gut microbiota and microRNA. Appl Microbiol Biotechnol 102: 4291-4303, 2018

58. Toden S, Okugawa Y, Buhrmann C, Nattamai D, Anguiano E, Baldwin N, Shakibaei M, Boland CR and Goel A: Novel evidence for curcumin and boswellic acid-induced chemoprevention through regulation of miR-34a and miR-27a in colorectal cancer. Cancer Prev Res (Phila) 8: 431-443, 2015

59. Li B, Shi C, Li B, Zhao JM and Wang L: The effects of Curcumin on HCT-116 cells proliferation and apoptosis via the miR-491/PEG10 pathway. J Cell Biochem 4: 3091-3098, 2018.

60. Gandhy SU, Kim K, Larsen L, Rosengren RJ and Safe S: Curcumin and synthetic analogs induce reactive oxygen species and decreases specificity protein $(\mathrm{Sp})$ transcription factors by targeting microRNAs. BMC Cancer 12: 564, 2012.

61. Dou H, Shen R, Tao J, Huang L, Shi H, Chen H, Wang Y and Wang T: Curcumin suppresses the colon cancer proliferation by inhibiting Wnt $/ \beta$-catenin pathways via miR-130a. Front Pharmacol 8: 877, 2017.

62. Nascimento-Gonçalves E, Faustino-Rocha AI, Seixas F, Ginja M, Colaço B, Ferreira R, Fardilha M and Oliveira PA: Modelling human prostate cancer: Rat models. Life Sci 203: 210-224, 2018.

63. Kanwal R, Plaga AR, Liu X, Shukla GC and Gupta S: MicroRNAs in prostate cancer: Functional role as biomarkers. Cancer Lett 407: 9-20, 2017.

64. Takayama KI,Misawa A and Inoue S: Significance of microRNAs in androgen signaling and prostate cancer progression. Cancers (Basel) 9: e102, 2017.

65. Cao H, Yu H, Feng Y, Chen L and Liang F: Curcumin inhibits prostate cancer by targeting PGK1 in the FOXD3/miR-143 axis. Cancer Chemother Pharmacol 79: 985-994, 2017.

66. Liu J, Li M, Wang Y and Luo J: Curcumin sensitizes prostate cancer cells to radiation partly via epigenetic activation of miR-143 and miR-143 mediated autophagy inhibition. J Drug Target 25: 645-652, 2017.

67. Liu T, Chi H, Chen J, Chen C, Huang Y, Xi H, Xue J and Si Y: Curcumin suppresses proliferation and in vitro invasion of human prostate cancer stem cells by ceRNA effect of miR-145 and lncRNA-ROR. Gene 631: 29-38, 2017.

68. Zhang H, Zheng J, Shen H, Huang Y, Liu T, Xi H and Chen C: Curcumin suppresses in vitro proliferation and invasion of human prostate cancer stem cells by modulating DLK1-DIO3 imprinted gene cluster microRNAs. Genet Test Mol Biomarkers 22: 43-50, 2018.

69. Goh JN, Loo SY, Datta A, Siveen KS, Yap WN, Cai W, Shin EM, Wang C, Kim JE, Chan M, et al: microRNAs in breast cancer: Regulatory roles governing the hallmarks of cancer. Biol Rev Camb Philos Soc 91: 409-428, 2016

70. Nassar FJ, Nasr R and Talhouk R: MicroRNAs as biomarkers for early breast cancer diagnosis, prognosis and therapy prediction. Pharmacol Ther 172: 34-49, 2017.

71. Wang X, Hang Y, Liu J, Hou Y, Wang N and Wang M: Anticancer effect of curcumin inhibits cell growth through miR-21/PTEN/Akt pathway in breast cancer cell. Oncol Lett 13: 4825-4831, 2017.

72. Li X, Xie W, Xie C, Huang C, Zhu J, Liang Z, Deng F, Zhu M, Zhu W, Wu R, et al: Curcumin modulates miR-19/PTEN/AKT/p53 axis to suppress bisphenol A-induced MCF-7 breast cancer cell proliferation. Phytother Res 28: 1553-1560, 2014.
73. Yang J, Cao Y, Sun J and Zhang Y: Curcumin reduces the expression of Bcl-2 by upregulating miR-15a and miR-16 in MCF-7 cells. Med Oncol 27: 1114-1118, 2010.

74. Norouzi S, Majeed M, Pirro M, Generali D and Sahebkar A Curcumin as an adjunct therapy and microRNA modulator in breast cancer. Curr Pharm Des 24: 171-177, 2018.

75. Guo J, Li W, Shi H, Xie X, Li L, Tang H, Wu M, Kong Y, Yang L, Gao J, et al: Synergistic effects of curcumin with emodin against the proliferation and invasion of breast cancer cells through upregulation of miR-34a. Mol Cell Biochem 382: 103-111, 2013.

76. Kronski E, Fiori ME, Barbieri O, Astigiano S, Mirisola V, Killian PH, Bruno A, Pagani A, Rovera F, Pfeffer U, et al: miR181b is induced by the chemopreventive polyphenol curcumin and inhibits breast cancer metastasis via down-regulation of the inflammatory cytokines CXCL1 and -2. Mol Oncol 8: 581-595, 2014.

77. Spence T, Bruce J, Yip KW and Liu FF: MicroRNAs in nasopharyngeal carcinoma. Chin Clin Oncol 5: 17, 2016.

78. Lee KT, Tan JK, Lam AK and Gan SY: MicroRNAs serving as potential biomarkers and therapeutic targets in nasopharyngeal carcinoma: A critical review. Crit Rev Oncol Hematol 103: 1-9, 2016.

79. Gao W, Chan JY and Wong TS: Curcumin exerts inhibitory effects on undifferentiated nasopharyngeal carcinoma by inhibiting the expression of miR-125a-5p. Clin Sci (Lond) 127: 571-579, 2014.

80. Feng S, Wang Y, Zhang R, Yang G, Liang Z, Wang Z and Zhang G: Curcumin exerts its antitumor activity through regulation of $\mathrm{miR}-7 / \mathrm{Skp} 2 / \mathrm{p} 21$ in nasopharyngeal carcinoma cells. OncoTargets Ther 10: 2377-2388, 2017.

81. Fan H, Shao M, Huang S, Liu Y, Liu J, Wang Z, Diao J, Liu Y, Tong LI and Fan Q: miR-593 mediates curcumin-induced radiosensitization of nasopharyngeal carcinoma cells via MDR1. Oncol Lett 11: 3729-3734, 2016.

82. Diab M, Muqbil I, Mohammad RM, Azmi AS and Philip PA: The role of microRNAs in the diagnosis and treatment of pancreatic adenocarcinoma. J Clin Med 5: E59, 2016.

83. Rachagani S, Macha MA, Heimann N, Seshacharyulu P, Haridas D, Chugh S and Batra SK: Clinical implications of miRNAs in the pathogenesis, diagnosis and therapy of pancreatic cancer. Adv Drug Deliv Rev 81: 16-33, 2015.

84. Chitkara D, Mittal A and Mahato RI: miRNAs in pancreatic cancer: Therapeutic potential, delivery challenges and strategies. Adv Drug Deliv Rev 81: 34-52, 2015.

85. Yang D, Li Y and Zhao D: Curcumin induces apoptotic cell death in human pancreatic cancer cells via the miR-340/XIAP signaling pathway. Oncol Lett 14: 1811-1816, 2017.

86. Ma J, Fang B, Zeng F, Pang H, Zhang J, Shi Y, Wu X, Cheng L, Ma C, Xia J and Wang Z: Curcumin inhibits cell growth and invasion through up-regulation of miR-7 in pancreatic cancer cells. Toxicol Lett 231: 82-91, 2014.

87. Sun M, Estrov Z, Ji Y, Coombes KR, Harris DH and Kurzrock R: Curcumin (diferuloylmethane) alters the expression profiles of microRNAs in human pancreatic cancer cells. Mol Cancer Ther 7: 464-473, 2008.

88. Siegel RL, Miller KD and Jemal A: Cancer statistics, 2019. CA Cancer J Clin 69: 7-34, 2019

89. Chen S, Wang Y, Zhou W, Li S, Peng J, Shi Z, Hu J, Liu YC, Ding $\mathrm{H}$, Lin $\mathrm{Y}$, et al: Identifying novel selective non-nucleoside DNA methyltransferase 1 inhibitors through docking-based virtual screening. J Med Chem 57: 9028-9041, 2014

90. Bertacchini J, Heidari N, Mediani L, Capitani S, Shahjahani M, Ahmadzadeh A and Saki N: Targeting PI3K/AKT/mTOR network for treatment of leukemia. Cell Mol Life Sci 72: 2337-2347, 2015.

91. Taverna S, Fontana S, Monteleone F, Pucci M, Saieva L, De Caro V, Cardinale VG, Giallombardo M, Vicario E, Rolfo C, et al: Curcumin modulates chronic myelogenous leukemia exosomes composition and affects angiogenic phenotype via exosomal miR-21. Oncotarget 7: 30420-30439, 2016.

92. Taverna S, Giallombardo M, Pucci M, Flugy A, Manno M, Raccosta S, Rolfo C, De Leo G and Alessandro R: Curcumin inhibits in vitro and in vivo chronic myelogenous leukemia cells growth: A possible role for exosomal disposal of miR-21. Oncotarget 6: 21918-21933, 2015.

93. Gao SM, Yang JJ, Chen CQ, Chen JJ, Ye LP, Wang LY, Wu JB, Xing CY and Yu K: Pure curcumin decreases the expression of WT1 by upregulation of miR-15a and miR-16-1 in leukemic cells. J Exp Clin Cancer Res 31: 27, 2012.

94. Nakamura K, Sawada K, Yoshimura A, Kinose Y, Nakatsuka E and Kimura T: Clinical relevance of circulating cell-free microRNAs in ovarian cancer. Mol Cancer 15: 48, 2016. 
95. Li SD, Zhang JR, Wang YQ and Wan XP: The role of microRNAs in ovarian cancer initiation and progression. J Cell Mol Med 14: 2240-2249, 2010.

96.Zhang J, Liu J, Xu X and Li L: Curcumin suppresses cisplatin resistance development partly via modulating extracellular vesicle-mediated transfer of MEG3 and miR-214 in ovarian cancer. Cancer Chemother Pharmacol 79: 479-487, 2017.

97. Zhao J, Pan Y, Li X, Zhang X, Xue Y, Wang T, Zhao S and Hou Y: Dihydroartemisinin and curcumin synergistically induce apoptosis in SKOV3 cells via upregulation of miR-124 targeting midkine. Cell Physiol Biochem 43: 589-601, 2017.

98.Zhao SF, Zhang X, Zhang XJ, Shi XQ, Yu ZJ and Kan QC: Induction of microRNA-9 mediates cytotoxicity of curcumin against SKOV3 ovarian cancer cells. Asian Pac J Cancer Prev 15: 3363-3368, 2014

99. Tahmasebi Mirgani M, Isacchi B, Sadeghizadeh M, Marra F, Bilia AR, Mowla SJ, Najafi F and Babaei E: Dendrosoma curcumin nanoformulation downregulates pluripotency genes via miR-145 activation in U87MG glioblastoma cells. In J Nanomedicine 9: 403-417, 2014.

100. Allegri L, Rosignolo F, Mio C, Filetti S, Baldan F and Damante G: Effects of nutraceuticals on anaplastic thyroid cancer cells. J Cancer Res Clin Oncol 144: 285-294, 2018.

101. Saini S, Arora S, Majid S, Shahryari V, Chen Y, Deng G, Yamamura S, Ueno K and Dahiya R: Curcumin modulates miRNA-203-mediated regulation of the Src-Akt axis in bladder cancer. Cancer Prev Res (Phila) 4: 1698-1709, 2011.

102.Zaman MS, Chauhan N, Yallapu MM, Gara RK, Maher DM, Kumari S, Sikander M, Khan S, Zafar N, Jaggi M and Chauhan SC: Curcumin nanoformulation for cervical cance treatment. Sci Rep 6: 20051, 2016.

103. Chen P, Wang H, Yang F, Chen H, He W and Wang J: Curcumin promotes osteosarcoma cell death by activating miR-125a/ERRo signal pathway. J Cell Biochem 118: 74-81, 2017.

104. Mou S, Zhou Z, He Y, Liu F and Gong L: Curcumin inhibits cell proliferation and promotes apoptosis of laryngeal cancer cells through Bcl-2 and PI3K/Akt, and by upregulating miR-15a. Oncol Lett 14: 4937-4942, 2017.

105. Zhang L, Peng D, Sood AK, Dang CV and Zhong X: Shedding light on the dark cancer genomes: Long noncoding RNAs as novel biomarkers and potential therapeutic targets for cancer. Mol Cancer Ther 17: 1816-1823, 2018.

106. Campos-Parra AD, Lopez-Urrutia E, Orozco Moreno LT, Lopez-Camarillo C, Meza-Menchaca T, Figueroa Gonzalez G, Bustamante Montes LP and Perez-Plasencia C: Long non-coding RNAs as new master regulators of resistance to systemic treatments in breast cancer. Int J Mol Sci 19: E2711, 2018.

107. Alvarez-Dominguez JR and Lodish HF: Emerging mechanisms of long noncoding RNA function during normal and malignant hematopoiesis. Blood 130: 1965-1975, 2017.

108. Huang Y: The novel regulatory role of lncRNA-miRNA-mRNA axis in cardiovascular diseases. J Cell Mol Med 22: 5768-5775, 2018
109. Corrà F, Agnoletto C, Minotti L, Baldassari F and Volinia S: The network of non-coding RNAs in cancer drug resistance. Front Oncol 8: 327, 2018.

110. Peng Z, Zhang C and Duan C: Functions and mechanisms of long noncoding RNAs in lung cancer. Onco Targets Ther 9: 4411-4424, 2016.

111. Wei MM and Zhou GB: Long non-coding RNAs and their roles in non-small-cell lung cancer. Genomics Proteomics Bioinformatics 14: 280-288, 2016.

112. Wang WH, Chen J, Zhang BR, Lu SJ, Wang F, Peng L, Dai JH and Sun YZ: Curcumin inhibits proliferation and enhances apoptosis in A549 cells by downregulating lncRNA UCA1. Pharmazie 73: 402-407, 2018

113. Luo J, Qu J, Wu DK, Lu ZL, Sun YS and Qu Q: Long non coding RNAs: A rising biotarget in colorectal cancer. Oncotarget 8 22187-22202, 2017

114. Li H, Ma SQ, Huang J, Chen XP and Zhou HH: Roles of long noncoding RNAs in colorectal cancer metastasis. Oncotarget 8 39859-39876, 2017.

115. Chen T, Yang P, Wang $\mathrm{H}$ and He ZY: Silence of long noncoding RNA PANDAR switches low-dose curcumin-induced senescence to apoptosis in colorectal cancer cells. Onco Targets Ther 10: 483-491, 2017.

116. Misawa A, Takayama KI and Inoue S: Long non-coding RNAs and prostate cancer. Cancer Sci 108: 2107-2114, 2017.

117. Mitobe Y, Takayama KI, Horie-Inoue K and Inoue S: Prostate cancer-associated lncRNAs. Cancer Lett 418: 159-166, 2018.

118. Wang J, Ye C, Xiong H, Shen Y, Lu Y, Zhou J and Wang L: Dysregulation of long non-coding RNA in breast cancer: An overview of mechanism and clinical implication. Oncotarget 8: 5508-5522, 2017.

119. Esmatabadi MJD, Motamedrad M and Sadeghizadeh M: Down-regulation of lncRNA, GAS5 decreases chemotherapeutic effect of dendrosomal curcumin (DNC) in breast cancer cells. Phytomedicine 42: 56-65, 2018.

120. Duguang L, Jin H, Xiaowei Q, Peng X, Xiaodong W, Zhennan L, Jianjun Q and Jie Y: The involvement of IncRNAs in the development and progression of pancreatic cancer. Cancer Biol Ther 18: 927-936, 2017

121. Huang X, Zhi X, Gao Y, Ta N, Jiang H and Zheng J: lncRNAs in pancreatic cancer. Oncotarget 7: 57379-57390, 2016.

122. Yoshida K, Toden S, Ravindranathan P, Han H and Goel A: Curcumin sensitizes pancreatic cancer cells to gemcitabine by attenuating PRC2 subunit EZH2, and the lncRNA PVT1 expression. Carcinogenesis 38: 1036-1046, 2017.

123. Nikpayam E, Tasharrofi B, Sarrafzadeh S and Ghafouri-Fard S: The role of long non-coding RNAs in ovarian cancer. Iran Biomed J 21: 3-15, 2017.

This work is licensed under a Creative Commons Attribution-NonCommercial-NoDerivatives 4.0 International (CC BY-NC-ND 4.0) License. 